\title{
Minimizing Complications During Retropubic Radical Prostatectomy - Is Ureteral Stenting NeCEssary?
}

\author{
B. Schlenker, C. Gratzke, M. Seitz, P. von Walter, D. Tilki, O. Reich, D. Zaak, C. G. Stief, M. J. Bader \\ Department of Urology, University Hospital Grosshadern, Ludwig-Maximilians-University Munich, Germany
}

\begin{abstract}
Objectives and Aims: To avoid damage to the ureters during bladder neck preparation in radical prostatectomy for prostate cancer, it may be helpful to insert ureteral stents temporarily or to intravenously administer indigo carmine dye for enhanced visualisation of ureteric orifices. We evaluated our bladder neck preserving technique at radical prostatectomy with regard to ureteric injuries.

Patients and Methods: We analysed 369 consecutive radical prostatectomies operated in our clinic in a bladder neck preserving technique. The following parameters were assessed in this retrospective study: number of prophylactic ureteric stent insertions, application of indigo carmine dye, observed injuries of the ureters by the surgeon, postoperative increase of serum creatinine and postoperative status of kidney ultrasound.

Results: In $7 / 369$ prostatectomies (1.90\%) a ureteric stent insertion was performed, indigo carmine was not applied to any patient at all, yet no intraoperative injury of a ureter was observed by a surgeon. No revision was necessary due to a ureteral injury within the observation period of one year after surgery. In $17 \mathrm{pa}-$ tients with preoperative normal creatinine value a pathological value was observed on the first postoperative day (mean $1.4 \mathrm{mg} / \mathrm{dl}$ ). In these patients no consecutive postrenal acute renal failure was observed, no hydronephrosis was monitored by ultrasound and no further intervention was necessary.

Conclusions: Bladder neck preserving operation technique does not implicate the need of prophylactic ureteric stent insertions and has no higher incidence of ureteric injuries.
\end{abstract}

Key words: prostate cancer; retropubic radical prostatectomy; intraoperative complication; ureter

\section{INTRODUCTION}

Cancer of the prostate (PCa) is the most common solid neoplasm in Europe with an incidence of 21.400 cases per 100.000 men [1]. In Germany, every year PCa is newly diagnosed in 58.000 men with an average age of 69 years and is currently the third most common cause of cancer death [2]. PCa in Germany is accounting for $10.1 \%$ of all tumor associated deaths [2]. Different treatment modalities are available for non-meta- static PCa. Besides radical prostatectomy (open retropubic / open perineal / laparoscopic / robot-assisted), other treatment options include percutaneous radiation, brachytherapy, watchful waiting or active surveillance [3]. Radical prostatectomy, however, is the only treatment that has shown an improved cancer-specific survival compared to conservative management [4]. The open retropubic radical prostatectomy was developed over 60 years ago and implies the removal of the entire prostate gland between the urethra and the bladder [5]. Despite improvements of the surgical approach like the 'nerve sparing' prostatectomy [6] there still are intra- and perioperative complications, e. g. prolonged urine leakage of the vesicourethral anastomosis in up to $15.4 \%$ of patients [3]. To avoid injuries of the ureteric orifices many surgeons use temporary ureteral stents or administer intravenously indigo carmine dye for enhanced visualisation especially when encountering an intravesical middle lobe during prostatectomy $[7,8]$. To improve early continence and reduce prolonged urine leakage of the vesicourethral anastomosis we use a bladder neck preserving operation technique [9]. The aim of the presented retrospective study was to investigate, if bladder neck preservation during open radical prostatectomy in a high volume center is associated with a higher risk of ureteral injuries and if additional procedures like temporary ureteral stenting or administration of indigo carmine dye for visualisation of the ureteric orifice are necessary.

\section{Patients AND Methods}

369 consecutive patients with histological confirmed PCa were treated in our hospital by open retropubic prostatectomy as described before $[10,11]$ and included in this retrospective study. Seven different surgeons with an experience of more than 100 radical prostatectomies each performed surgical intervention. All patients underwent routine preoperative examinations including abdominal ultrasound, chest X-ray and blood tests including creatinine value. On the first day after surgery, blood examinations were repeated routinely to exclude significant bleeding or other perioperative complications (e. g. urine leakage due to ureteral injury or an insufficient vesicourethral anastomosis). If blood testing showed pathological values or the patient was clinically conspicuous, the test was repeated latest the next day. In our laboratory standard, for men 
a creatinine level of 0.5 to $1.2 \mathrm{mg} / \mathrm{dl}$ is defined as non-pathological. Complete pre- and postoperative laboratory data were available for 263/369 patients. After discharge of hospital, the follow-up was performed by telephone interviews either of the patient, the visiting urologist or general practitioners one year after surgery. Specifically, every patient with pathological creatinine value during hospital stay underwent repeated blood testing. Furthermore it was investigated if the patient underwent any additional surgical procedure (e. g. ureteral stenting, percutaneous nephrostomy or ureteral reconstruction) due to a ureteral injury during prostatectomy.

\section{Statistical ANALYsis}

All data are expressed as mean \pm standard error of mean (SEM) calculated by using standard statistical methods.

\section{RESULTS}

Mean age at first diagnosis of prostate cancer was 63.7 \pm 0.3 years. During radical prostatectomy no surgeon observed any intraoperative injury of a ureter; neither ureteral reconstruction was performed. Indigo carmine dye was not applied at all. In 7/369 prostatectomies $(1.90 \%)$ a ureteric stent was inserted temporarily and removed either before closure of the last anastomosis sutures or $6-8$ weeks after radical prostatectomy by transurethral cystoscopy. No patient underwent any additional surgery due to a ureteral injury during follow-up.

Complete laboratory data were available of $263 / 369$ patients $(71.3 \%)$. In $17 / 263(6.5 \%)$ patients with preoperative normal creatinine value a pathological value was observed on the first postoperative day. Mean creatinine value in these patients before surgery was $1.1 \pm 0.02 \mathrm{mg} / \mathrm{dl}$, postoperatively $1.4 \pm 0.04$ $\mathrm{mg} / \mathrm{dl}$. Acute postrenal renal failure was excluded by abdominal ultrasound examination, a significant hydronephrosis was not seen in any case. All pathological creatinine values returned to preoperative level without any surgical intervention.

\section{Discussion}

During the last decades, radical prostatectomy has become a standard treatment for localized prostate cancer. In high volume surgical centers complication rates tend to be lower than in small centers with fewer than 50 prostatectomies per year $[12,13]$. With an evolving surgical technique, functional long-term results of continence and erectile function have dramatically improved [6]. For selected patients, continence rates of up to $99 \%$ after one year [9] and restored erectile function in up to $50 \%$ are reported [14]. Despite good functional long-term results there is still a risk of perioperative complications. In experienced hands the total perioperative complication rate may be as low as $1.8 \%-10 \%[15,16]$. The most common intraoperative complication is significant hemorrhage arising from venous structures and requiring blood transfusion [7]. Mean blood loss in historic series is reported to be as high as $1500 \mathrm{ml}$ [15], more recent publications report $150-300 \mathrm{ml}$ for experienced surgeons $[11,17]$. Besides hemorrhage, rectal injury and obturator nerve injury during pelvic lymphadenectomy are rare complications in recent series [8]. Ureteral injuries are reported in $0-4.7 \%$ [15-21]. There are no detailed reports about predisposing factors for ureteral damage. The injuries seem to occur most often during dissection of the posterior aspect of the bladder neck especially in patients with significant benign prostatic hyperplasia and J-hooking of the ureters [7,8]. In our own series consisting of 369 consecutive prostatectomies there were no ureteral injuries noticed. During prostatectomy in seven patients a ureteral stent was temporary used to protect the ureteral orifice during dissection of the bladder neck. All surgical procedures could be performed without obvious intraoperativley injuries to the ureter and without the need for a ureteral reconstruction. Indigo carmine dye was not applied at all, which might be due to personal preference of the urologic surgeons. Summarizing our data, there were no ureteral injuries and the use of ureteral stents was limited to single cases. This might indicate that in experienced hands a routinely stenting of ureters during prostatectomy is not necessary.

A limitation of the study is its retrospective nature. We did, however, include only patients with a detailed follow-up.

\section{CONCLUSIONS}

In a high volume surgical center setting, the risk for a ureteral injury during open radical prostatectomy is very low. Routinely performed ureteral stenting is not necessary but may be helpful in selected patients.

\section{REFERENCES}

1. Boyle P, Ferlay J. Cancer incidence and mortality in Europe. Ann Oncol. 2005; 16: 481.

2. Krebs in Deutschland 2003 - 2004. Häufigkeiten und Trends. 6th ed. Berlin: Robert Koch-Institut und die Gesellschaft der epidemiologischen Krebsregister in Deutschland e. V., 2008

3. Heidenreich A, Aus G, Bolla M, Joniau S, Matveev VB, Schmid HP, Zattoni F. EAU guidelines on prostate cancer. Eur Urol. 2008; 53: 68.

4. Bill-Axelson A, Holmberg L, Filen F, Ruutu M, Garmo $\mathrm{H}$, Busch C, Nordling S, Haggman M, Andersson SO, Bratell S, Spangberg A, Palmgren J, Adami HO, Johansson JE. Radical prostatectomy versus watchful waiting in localized prostate cancer: the Scandinavian prostate cancer group-4 randomized trial. J Natl Cancer Inst. 2008; 100: 1144.

5. Memmelaar J. Total prostatovesiculectomy; retropubic approach. J Urol. 1949; 62: 340.

6. Walsh PC, Donker PJ. Impotence following radical prostatectomy: insight into etiology and prevention. J Urol. 1982 ;128: 492.

7. Wein A, Kavoussi L, Novick A, Partin A, Peters C. Campbell-Walsh Urology, 9th ed. Saunders Elsevier, 2007

8. Shekarriz B, Upadhyay J, Wood DP. Intraoperative, perioperative, and long-term complications of radical prostatectomy. Urol Clin North Am. 2001; 28: 639.

9. Kessler TM, Burkhard FC, Studer UE. Nerve-sparing open radical retropubic prostatectomy. Eur Urol. 2007; 51: 90. 
10. Karl A, Buchner A, Becker H, Staehler M, Seitz M, Stief C. Perioperative blood loss in open retropubic radical prostatectomy - Is it safe to get operated at an educational hospital? Eur J Med Res. 2009; 14: 292.

11. Stief CG. Apical dissection during radical retropubic prostatectomy without ligature. World J Urol. 2003; 21: 139.

12. Hollenbeck BK, Dunn RL, Miller DC, Daignault S, Taub DA, Wei JT. Volume-based referral for cancer surgery: informing the debate. J Clin Oncol. 2007; 25: 91.

13. Nuttall M, van der Meulen J, Phillips N, Sharpin C, Gillatt D, McIntosh G, Emberton M. A systematic review and critique of the literature relating hospital or surgeon volume to health outcomes for 3 urological cancer procedures. J Urol. 172: 2004; 2145.

14. Dahl DM, Barry MJ, McGovern FJ, Chang Y, WalkerCorkery E, McDougal WS. A prospective study of symptom distress and return to baseline function after open versus laparoscopic radical prostatectomy. J Urol. 2009; 182: 956.

15. Catalona WJ, Carvalhal GF, Mager DE, Smith DS. Potency, continence and complication rates in 1,870 consecutive radical retropubic prostatectomies. J Urol. 1999; 162 : 433.

16. Lepor H, Kaci L. Contemporary evaluation of operative parameters and complications related to open radical retropubic prostatectomy. Urology. 2003; 62: 702.

17. Leandri P, Rossignol G, Gautier JR, Ramon J. Radical retropubic prostatectomy: morbidity and quality of life. Experience with 620 consecutive cases. J Urol. 1992; 147 : 883.
18. Igel TC, Barrett DM, Segura JW, Benson RC, Jr, Rife C C. Perioperative and postoperative complications from bilateral pelvic lymphadenectomy and radical retropubic prostatectomy. J Urol. 1987; 137: 1189.

19. Gheiler EL, Lovisolo JA, Tiguert R, Tefilli MV, Grayson T, Oldford G, Powell IJ, Famiglietti G, Banerjee M, Pontes JE, Wood DP, Jr. Results of a clinical care pathway for radical prostatectomy patients in an open hospital - multiphysician system. Eur Urol. 1999; 35: 210.

20. Hammerer P, Hubner D, Gonnermann D, Huland H. [Perioperative and postoperative complications of pelvic lymphadenectomy and radical prostatectomy in 320 consecutive patients]. Urologe A. 1995; 34: 334.

21. Hautmann RE, Sauter TW, Wenderoth UK. Radical retropubic prostatectomy: morbidity and urinary continence in 418 consecutive cases. Urology. 1994; 43: 47.

Received: November 2, 2009 / Accepted: November 30, 2009

Address for correspondence:

Boris Schlenker, M.D.

Department of Urology

University Hospital Grosshadern

Ludwig-Maximilians-University Munich

Marchioninistr. 15

81377 Munich

Germany

Tel.: $\quad+49-89-7095-0$

Fax: +49-89-7095-8744

E-mail: boris.schlenker@med.uni-muenchen.de 